\title{
World Heritage meets Smart City in an Urban- Educational Hackathon in Rauma
}

\author{
Anu Helena Suominen, Seija Halvari, Jari Jussila
}

\author{
" The world as we have created it is a process of our thinking. It \\ cannot be changed without changing our thinking." \\ Albert Einstein \\ Nobel Prize in Physics (1921)
}

\begin{abstract}
UNESCO World Heritage cities can become smart cities if they take into account their cultural heritage and integrate diverse actors, including universities in their innovation practices. This article addresses the hackathon as an innovation contest method in the urban and educational context. Specifically, it concentrates on hackathon design, particularly the focus of the event, as well as the outputs. Although the design plays an integral part in a hackathon, particularly in goal achievement, design has not yet been thoroughly studied in mainly descriptive hackathon research. To address the subject, this article presents a case study of a dual-focused, i.e., combined urban and educational hackathon in the City of Rauma, which has a World Heritage Old Town that aims to integrate its historical uniqueness with modern city services. As a result, the article portrays the process and outputs of a hackathon carried out with the collaboration of two higher education institutions (HEIs) and the Entrepreneur Association of Rauma. Presenting conclusions for both academics and the public sector, the article contributes to the literature on urban and educational hackathons in smart cities with a heritage context.
\end{abstract}

\section{Introduction}

During recent years, the 'smart city' concept has emerged in literature (e.g., Kunttu, 2019; Markkula \& Kune, 2018; Öberg, Graham, \& Hennelly, 2017; Visvizi \& Lytras, 2018). Inherently, the smart city concept includes urban innovation; therefore, simply developing and applying technology is not enough for success. For cities to be 'smart,' they also have to be innovative, apply new ways of thinking among businesses, citizens, and academia, as well as integrate diverse actors, especially universities, in their innovation practices (Kunttu, 2019; Markkula \& Kune, 2018).

At their best, smart cities incorporate two views: technology and people. People are the biggest challenge, since what is required is the creation of an open mindset and a participatory attitude toward rethinking the future (Mulder, 2014). When properly managed, cultural heritage may enhance the livability of the surrounding areas and sustain productivity (Roders \& van Oers, 2011). Thus, inhabited UNESCO World Heritage cities can also become smart only if they take their cultural heritage into account in their smart city concept and integrate diverse actors, including universities, in their innovation practices. Thus, there is a need for participatory methods that would bring together multiple stakeholders, especially universities, to innovate the smart future of inhabited urban cities with invaluable cultural heritage.

As a participatory method, hackathons, provide a promising methodology and have spread from IT to other sectors. Hackathons are used in education, the corporate sector, and by city organizations, for example, as an innovative exploration method for idea generation, selection, and prototyping (Granados \& ParejaEastaway, 2019; Pe-Than et al., 2019). Hackathons as a type of innovation contest have been defined as "a short bounded-time event of creation and ceremony processes of innovation, carried out in radical collocation and coopetition of teams to solve a challenge" (Halvari et al. 2019, p. 12). The public sector has also used innovative methods in so-called civic hackathons (e.g., Almirall, Lee, \& Majchrzak, 2014) and urban hackathons (e.g., Pogačar \& Žižek, 2016).

However, hackathon design elements and their effects 


\title{
World Heritage meets Smart City in an Urban-Educational Hackathon in Rauma
}

\author{
Anu Helena Suominen, Seija Halvari \& Jari Jussila
}

on event goal achievement is still under-researched (PeThan et al., 2019). This article studies hackathon design elements, the event process, and its outputs, particularly from the viewpoint of one hackathon design element, i.e. focus. We aim to clarify how hackathons are designed with multiple foci, especially the dual focus of urban-educational hackathons, to derive set goals. The study describes a case in the Finnish UNESCO World Heritage town of Rauma, with a student group of higher education institutions (HEIs) participating in a hackathon in the city context generating novel ideas. The event did not involve coding.

Our research questions are:

What kind of process and practises did a hackathon event, designed with a dual-focus, i.e., combined educational-urban hackathon, consist of?

What kind of output did a combined educationalurban hackathon achieve in terms of its dual-focus and goal setting?

In the pursuit of our research aims, the article is structured as follows. In the introduction, we first acknowledge the need to study the hackathon with a multiple focus in the educational and urban context. In the second section, the literature regarding smart cities and hackathons is discussed. The method and case description involve the presentation of, as well as grounds for, an empirical case study with students innovating in the smart city context. In the results, we describe the process and innovation outputs of a dualfocus hackathon. In the conclusions, we contemplate the results of a multi-focus, educational-urban hackathon in a smart city with a heritage context, and its significance to innovation methodology.

\section{Smart Cities and Hackathons}

\section{Smart city concept}

During recent years, the 'smart city' concept has emerged in the literature. A smart city may refer to a city as a geographical location, or as a municipal administration (Öberg et al., 2017), and the concept has been used in contexts ranging from megacities, with total populations of 10 million people or more, to a town or a village (Visvizi \& Lytras, 2018). Dameri (2013, p. 2549) defines a smart city as: “a well-defined geographical area, in which high technologies such as ICT, logistics, energy production, and so on, cooperate to create benefits for citizens in terms of well-being, inclusion and participation, environmental quality, intelligent development; it is governed by a well-defined pool of subjects, able to state the rules and policy for the city government and development." However, some cities that were established some time ago and have preserved their cultural heritage are listed as UNESCO World Heritage cities.

There are three types of heritage cities: 1) towns that are no longer inhabited, i.e., urban archaeological sites such as Palmyra in Syria, 2) inhabited historic towns, such as Djenne in Mali, Macau in China, and 3) new towns of the twentieth century, such as Brasilia in Brazil (Roders \& van Oers, 2011). Naturally, the inhabited cities must strike a balance between their heritage and the urban demands of their inhabitants and visitors. Yet, acknowledging the cultural heritage and including it in the smart city concept, World Heritage cities can also be smart cities. According to Ojasalo and Kauppinen (2018), urban innovation is at the heart of the smart city concept. Moreover, "the 'smartness' of a region relates to its capacity to leverage its human, structural, and relational capital, and its ability to integrate diverse actors in the region's innovation practice." (Markkula \& Kune 2018, p. 7) At best, a smart city combines two worlds: it is people-centered, values-active citizenship that embraces community-driven innovation, and is new technology-oriented. However, although participatory innovation is needed, the biggest challenges are the creation of an open mindset and a participatory attitude to rethink the future. (Mulder, 2014)

\section{Hackathon as an innovation contest}

Hackathons have their roots in programming in the 1960s (Leckart, 2012; Pe-Than \& Herbsleb, 2019; Zukin \& Papadantonakis, 2017). The current hackathon approach is a relatively novel one (Pe-Than et al., 2019), which focuses on the rapid and iterative development of small but scalable projects, and is considered a bottom-up approach (Chowdhury, 2018). The spread of the concept to other domains has caused proliferation (Angarita \& Nolte, 2019), but generally, hackathons are regarded as innovation contests (Hartmann, Mainka, \& Stock, 2019a), or competitions (Hartmann, Mainka, \& Stock, 2019b). Moreover, hackathons are regarded as innovation practices, which contribute to innovation in two ways: by promoting exploration activities, such as new external solutions, and by enhancing some preconditions of innovation, e.g., attracting talent or building a community of experts (Granados \& ParejaEastaway, 2019). In their conceptualization of the hackathon (Halvari et al., 2019), have identified the core attributes of hackathons. The first attribute is coopetition, i.e., simultaneous competition and 


\section{World Heritage meets Smart City in an Urban-Educational Hackathon in Rauma}

\section{Anu Helena Suominen, Seija Halvari \& Jari Jussila}

collaboration, which can exist on the organizational level as well as the individual, team, or network level (Bouncken, Gast, Kraus, \& Bogers, 2015). Besides competition, collaboration is an inherent characteristic of hackathons (Almirall et al., 2014; Briscoe \& Mulligan, 2014; Granados \& Pareja-Eastaway, 2019; Hartmann et al., 2019a, 2019b; Kienzler \& Fontanesi, 2017; Leckart, 2012; Pe-Than et al., 2019; Rosell, Kumar, \& Shepherd, 2014). Furthermore, hackathons are regarded as one of the most widespread collaborative practices (Granados \& Pareja-Eastaway, 2019). The second attribute is radical collocation, a situation where team members are together in a physical space for the duration of the project (Pe-Than et al., 2019; Pe-Than \& Herbsleb, 2019; Teasley, Covi, Krishnan, \& Olson, 2000). The concept of radical collocation also incorporates cooperation in teams. The third attribute is the hackathon's duration as an intense, short-term, time-bound event (Chowdhury, 2018; Kienzler \& Fontanesi, 2017; Lodato \& DiSalvo, 2015; Pe-Than et al., 2019; Pe-Than \& Herbsleb, 2019). As the fourth and fifth attributes, the hackathon event includes two processes: it starts with a creation process and is followed by a ceremony process (Halvari et al., 2019). The ceremony incorporates the presentation of the output with a pitch for example, as well as recognition of the results, sometimes including rewards ranging from non-monetary to monetary (Kienzler \& Fontanesi, 2017; Pe-Than et al., 2019). Hackathons have been adopted in many domains and for multiple usages besides only coding (Leckart, 2012; Zukin \& Papadantonakis, 2017): as an educational method (Porras et al., 2019), a way to crowdsource solutions (Gama, 2017), to find new potential employees (Komssi et al., 2015; Pe-Than \& Herbsleb, 2019), to attain public engagement and collaboration between citizens (Gama, 2017), the creation of prototypes, and possible new business formation (Komssi et al., 2015). As events, they yield learning, create new social connections, and have the potential to foster innovation.

The features of hackathons that cultivate creativity and innovation are: the diverse expertise and experience of participants; interruption-free and focused work hours; processes, goals, and management, which occur outside the usual constraints; opportunity to run a project, assess its feasibility, and uncover potential pitfalls with minimal risk to daily operations; and a chance for participants to work on something they are passionate about (Pe-Than et al., 2019). The entire hackathon process is divided into the pre-hackathon, the hackathon event itself, and post-hackathon processes (Granados \& Pareja-Eastaway, 2019; Komssi et al., 2015; Rosell et al., 2014), and as a process, hackathons have both inputs and outputs (Komssi et al., 2015). Due to its attributes, a hackathon event has particular design choices (Pe-Than et al., 2019), or design elements (Adamczyk, Bullinger, \& Möslein, 2012), such as focus, (e.g., educational, urban, civic, industrial), goals (e.g., learning, prototyping, problem solving), task setting (e.g., bounded or unbounded tasks of the event), participants, team formation, etc., which act as the hackathon event inputs. Team or group formation in educational events may occur as random selection and development, either by self-grouping, the educator's choice, or in addition, by applying specific criteria that can vary in terms of background, personality, ethnicity, and gender etc. (Dascalu, Bodea, Lytras, De Pablos, \& Burlacu, 2014).

\section{Issue-oriented, Urban and Civic hackathons}

Societal and environmental change together with the development of information technologies are changing urban planning. Pogačar and Žižek (2016) emphasize that today, due to the requirements of flexibility, usability, and openness in urban space, new alternative approaches to urban planning are emerging, especially in the context of urban renewal. Open data for strategic planning and day-to-day operations, as well as stakeholder involvement are both necessary (Pogačar and Žižek, 2016).

Corporate hackathons are considered to favor the production of technical solutions for business opportunities, whereas issue-oriented events put social questions at the centre, such as environmental conditions or food systems. Civic hackathons are regarded as one subset of issue-oriented hackathons, which focus on governance and public life. In civic hackathons, activists, citizens, entrepreneurs, and coders are drawn together to address social conditions and their consequences. (DiSalvo, Gregg, \& Lodato, 2014) Civic hackathons are open to the broad public and participation is via an accessible platform (Pogačar \& Žižek, 2016). Civic hackathons provide ad-hoc experiments in new conceptions of citizenship, with audience outputs and applications that envision citizenship. (DiSalvo et al., 2014) Pogačar \& Žižek (2016) consider urban hackathons as a form of civic hackathon, which use a similar approach in the field of urban development and renewal.

The focus of an urban hackathon is exclusively on the problems of the urban environment, acknowledging the importance of open data, public participation, and community collaboration. As with the general term of hackathon, there is also a proliferation in the use of civic hackathon as a term, but at their core, they are similar events of diverse groups of people, e.g., IT specialists, 


\section{World Heritage meets Smart City in an Urban-Educational Hackathon in Rauma}

\section{Anu Helena Suominen, Seija Halvari \& Jari Jussila}

communicators, community organizers, other specialists, and activists creatively and collaboratively contributing to problem solving in the domain. Similarly, as with general hackathons, civic hackathons vary in focus, event format, topics, and approaches (Pogačar \& Žižek, 2016). In the view of Pogačar and Žižek, the aim of urban hackathons may range from pure coding to "decision making, generating public initiatives with concrete proposals, compiling document drafts with solid argumentation based on open data and strategic foresight, etc." (Pogačar \& Žižek 2016, p. 1973). In the literature, both positive and negative views have been presented regarding civic hackathons. The positive aspects are the output of valuable open data crowdsourced apps with the investment of prizes and publicity. The utility and quality of the apps, and the hackathon process or scope have received criticism, yet this is mostly based on anecdotal evidence, and rigorous empirical evidence on the claims has not been found. However, it has been verified that the developers' experience affects the requirements and compromises the utility and relevance of applications (Gama, 2017). Many researchers neveretheless point out that the research on civic hackathons is scarce and limited, hence evidence of hackathon outputs is also scarce. Therefore, more research is needed to assess the impacts, outcomes, and value of their deployment, as well as the stakeholders that derive value from them (Gama, 2017; Johnson \& Robinson, 2014). This suggests that one simple way to measure value is through descriptive statistics surrounding contest inputs and outputs (Johnson \& Robinson, 2014).

\section{Methods and Case Description}

We chose the case study approach (e.g., Siggelkow, 2007) to study the innovation contest of a hackathon with a dual educational and urban focus. In our case study, the theory of smart cities and hackathons was identified via literature. Next, a single case study was carried out in 2018 using action research methodology in an educational hackathon where urban issues were innovated in Rauma, a town of 39,360 inhabitants in Finland (Statistics Finland, 2018). The town of Rauma was established in 1442, and the Old Town of Rauma with its wooden buildings received UNESCO World heritage status in 1991. The participants of the hackathon were students from one Research, Development and Innovation (RDI) class in an HEI, majoring in either technical or business subjects. The research material consisted of field notes of observations made before, during, and after the hackathon. The hackathon was arranged in collaboration between two HEIs and the Entrepreneur Association of Rauma.
The purpose of the empirical research was to study a hackathon with the dual focus of a combined educational and urban hackathon, its design, process, and outputs. The hackathon concerned the development needs of a city with an inhabited cultural heritage, i.e., Old Rauma, with the new commercial centre planned in the proximity. The case was chosen due to its idiosyncrasy: there are only a few descriptive reports on hackathons with multiple foci, firstly in an educational context, and secondly in the context of smart cities with cultural heritage where innovation is carried out beyond coding. Therefore, the case is interesting for theory building regarding the hackathon type of innovation contest, as a way to enhance innovation management within both HEIs and cities.

\section{Results of the Case Study}

\section{Hackathon with dual focus in Rauma}

When the observed hackathon is described in terms of attributes and themes (Table 1), the dual focus of the hackathon is revealed. It has the training elements of an educational hackathon, yet the task setting is aimed at solving urban issues.

\section{Hackathon process}

Figure 1 describes the entire hackathon process in three phases: pre-hackathon, hackathon event itself, and posthackathon. In the pre-hackathon phase, the design elements were planned according to the focus of the hackathon. Due to the dual focus, both educational and urban hackathon characteristics had to be taken into account in the pre-hackathon phase design. As the focus was two-fold: educational and urban, likewise the goals of the hackathon were dual. They were to, 1) produce learning of innovation, and, 2) yield innovations that benefit the city aiming to combine its World Heritage with its urban needs.

As an educational hackathon, learning elements had to be incorporated. Since the hackathon event duration was designed to be short, training for the participants was provided in the pre-hackathon phase via innovation lectures and short video clips of four creative methods prepared by lecturers. The four creative methods presented were: 1) Transformation technique (Cross, 2008), 2) Synectics with fantasy analogies (Cross, 2008), an analogy method which is particularly a type of the distant analogy method, 3) Trace matrix for business chains (Kärkkäinen, Piippo, \& Tuominen, 2001), which helps to describe complex business chains and trace back requirements for the company from even a remote customer's stakeholders and trends, and 4) a novel 3+1 


\title{
World Heritage meets Smart City in an Urban-Educational Hackathon in Rauma
}

\author{
Anu Helena Suominen, Seija Halvari \& Jari Jussila
}

Table 1. The Old Rauma Hackathon presented with hackathon concept attributes and themes

\begin{tabular}{|c|c|c|c|}
\hline \multicolumn{4}{|c|}{ Old Rauma Hackathon } \\
\hline Theme & & Attribute & Old Rauma Case \\
\hline \multirow[t]{4}{*}{ Coopetition } & 1 & Team & $\begin{array}{l}\text { - } 2 \text { teams with } 4 \text { participants, } 1 \text { team with } 3 \text { participants: total } 3 \text { teams } \\
\text { with } 11 \text { participants }\end{array}$ \\
\hline & 2 & Challenge & $\begin{array}{l}\text { - To create ideas for Old Rauma to add value to its users with a new } \\
\text { commercial centre to be built in the proximity } \\
\text { - To learn innovation methods }\end{array}$ \\
\hline & 3 & $\begin{array}{l}\text { Creation } \\
\text { process }\end{array}$ & $\begin{array}{l}\text { - Background information from an Old Rauma entrepreneur who is the } \\
\text { chairman of The Entrepreneur Association of Rauma } \\
\text { - Innovation exercises used for drafting the final ideas } \\
\text { - Pitching exercise } \\
\text { - Team formation } \\
\text { - Continual Ideation process }\end{array}$ \\
\hline & 4 & $\begin{array}{l}\text { Ceremony } \\
\text { process }\end{array}$ & $\begin{array}{l}\text { - Idea pitching by each group } \\
\text { - Jury: comments on each presentation } \\
\text { - Winner: voting by each participant based on pre-defined criteria }\end{array}$ \\
\hline \multirow{2}{*}{$\begin{array}{r}\text { Radical } \\
\text { Collocation }\end{array}$} & 5 & Collaboration & $\begin{array}{l}\text { - Participants/teams: Students } \\
\text { - Organizers: } 2 \text { HEIs in cooperation } \\
\text { - Domain: Entrepreneur Association }\end{array}$ \\
\hline & 6 & $\begin{array}{l}\text { Collocation } \\
\text { Consistency }\end{array}$ & $\begin{array}{l}\text { - Public library in close proximity of Old Rauma } \\
\text { - Coffee/tea and fruits as a complimentary snack } \\
\text { - Intensive and consistent }\end{array}$ \\
\hline $\begin{array}{l}\text { Short time- } \\
\text { bounded event }\end{array}$ & 8 & $\begin{array}{l}\text { Short } \\
\text { duration }\end{array}$ & $\begin{array}{l}\text { - Duration } 10 \text { hours + preliminary innovation exercise, as well as reading } \\
\text { and report writing after the event }\end{array}$ \\
\hline
\end{tabular}

method, where an idea is examined via four views (Suominen, Jussila, Lundell, Mikkola, \& AramoImmonen, 2018). Training sessions were also provided during the event, i.e., there was a pitch training, an 'Idea Walk' (Slåen, Mantere, Tollet, \& Karisto, 2003), and an 'Open Space', which were designed in the prehackathon phase. The event was designed to be held in the facilities of the Rauma public library. This location was chosen due to its close proximity to Old Rauma, and the library's open and free space, which provides both concrete and online knowledge that manifests the 'smart city' activities. The participants were predetermined as they were students of one HEI's RDIcourse. The students participating were from various cities outside Rauma, and were mostly unfamiliar with each other prior to the event. Both the team formation and sizes were voluntary, and team formation was designed to occur during the hackathon event.

In the event phase, the hackathon started with innovation exercises, a warm-up and pitch training with the NABC model (Carlson \& Wilmot, 2006). The aim of this was to allow the participants to get to know each other, while embarking on the ideation process. Team formation was merged into the innovation exercises, and team sizes were voluntarily formed. The goal setting aimed at fulfilling the domain's real-life need to make Old Rauma more viable. As the participants were students, the set task was bounded.

Background information for the task was given by the Chairman of the Rauma Entrepreneur Association, who has been an entrepreneur in Old Rauma for four decades. He described the urban challenges of a World Heritage city with the modern needs of inhabitants and visitors. As the main challenges, he listed the change of generations, the revolution in retail, digitalization and e-commerce, and a changing environment. Thereafter, the task was described by the organizing HEI lecturers as follows:

What kind of solution for Rauma city centre would produce added value for some user group? Or, Develop a novel solution that would create value for some user groups of the city centre of Rauma. The solution may be physical, intangible, digital, or a combination. 


\section{World Heritage meets Smart City in an Urban-Educational Hackathon in Rauma}

\section{Anu Helena Suominen, Seija Halvari \& Jari Jussila}

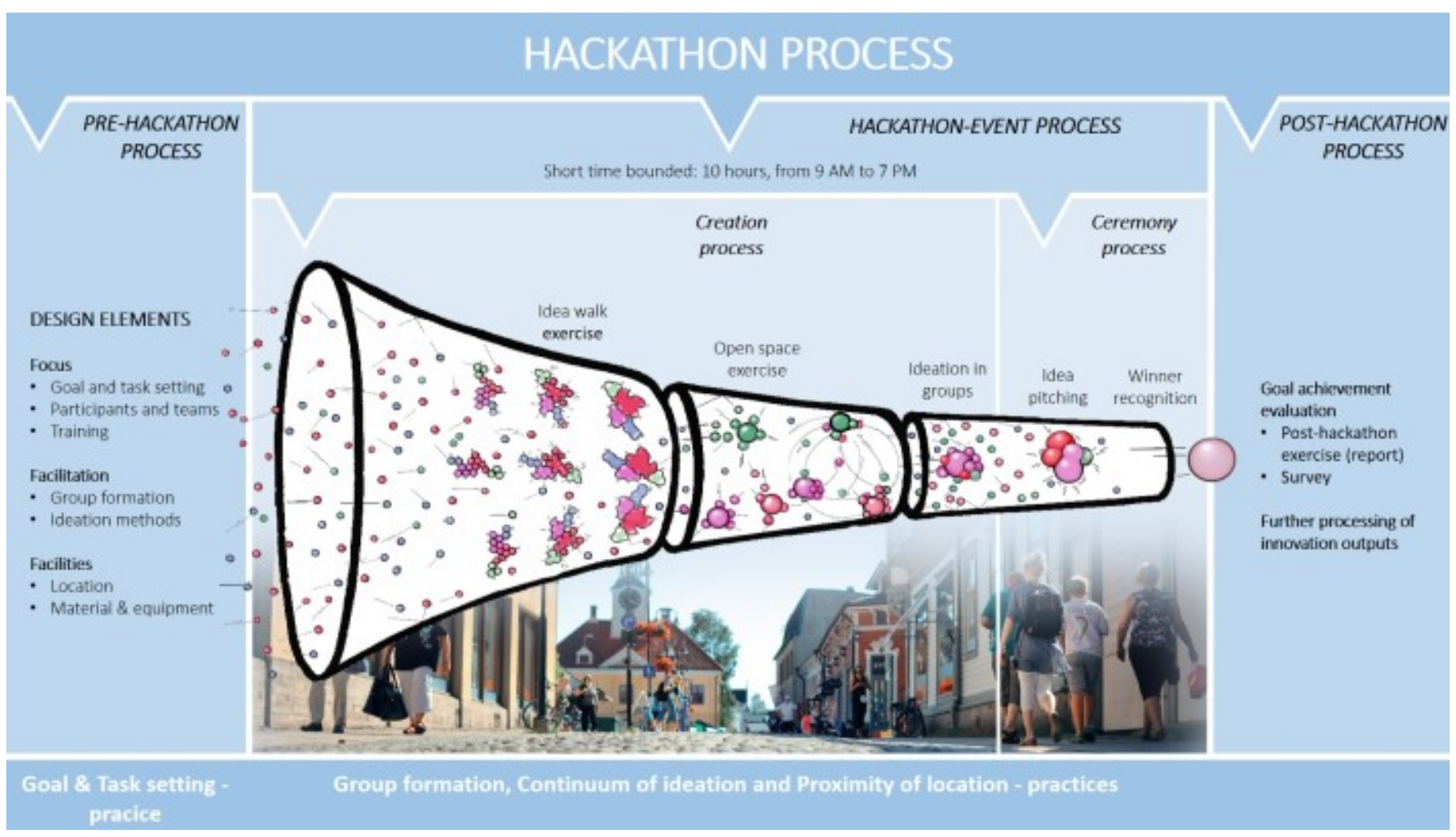

Figure 1. Hackathon process

The creation process started with the Idea Walk. The Idea Walk method is a version of brainstorming, where ideation is carried out individually or in small groups. The aim of an Idea Walk is to support the broadening of views, and to yield as many approaches toward the problem as possible. The hackathon's Idea Walk started with large empty sheets, each of which had a different topic, such as possibilities, threats, and potential users. Each participant wandered around to the sheets, and added their ideas on top of others'. The method produced lots of ideas, which were grouped, without evaluation, and presented to all of the participants, as well as left on display for inspiration during the event. The Idea Walk produced seven idea areas (Table 2), and was followed by using the Open Space method, where voluntary students presented their idea and invited others to join their team. Initially, four teams formed in the Open Space period. Yet only two teams joined forces in the end, after students were able to discuss all of the presented topics. Thus, the essence of these event methods is self-direction. In the Open Space, the students discussed five ideas (Table 2). After the Open Space, the Rauma hackathon continued with three teams working towards their final solutions.

The work on the hackathon task was then continued with the possibility for facilitation and mentoring with the lecturers. The students had three hours to work on their solutions. Some students used the opportunity to do a walkabout in Old Rauma, and test their ideas in an authentic environment. The celebration process was started three hours later, after the participants returned

Table 2. The ideas results of Idea Walk and Open Space ideations

\begin{tabular}{lc}
\hline Idea Walk ideas & Open Space ideas \\
\hline 1. User segments and their services & 1. Glass-topped walking area \\
2.\& 3. Threats and Opportunities of the area & 2. Transportation portal \\
4. Reasons for people to gather in certain areas & 3. City walking tour with an app \\
$\begin{array}{l}\text { 5. Technology for value creation } \\
\text { 6. Needs to be satisfied }\end{array}$ & $4 . \quad$ Community and collaborational mass \\
7. Organizations to benefit from the area & 5. Pop-up days \\
\hline
\end{tabular}




\section{World Heritage meets Smart City in an Urban-Educational Hackathon in Rauma}

\section{Anu Helena Suominen, Seija Halvari \& Jari Jussila}

to the library to pitch their ideas to a three-person jury, with two members from the Entrepreneur Association and one observing lecturer. The length of the pitch was a maximum of three minutes. After the pitches, each of the groups collected a small reward, and the winning team received a gift card for a restaurant located in Old Rauma. In the post-hackathon phase, the student teams produced a report, which was then evaluated by the lecturers, as part of the educational hackathon goal was learning. Furthermore, a post-hackathon survey was prepared by the lecturers and filled in by the students right after the event. Moreover, a summary of the event and its outputs was delivered to the Rauma Entrepreneur Association, although a follow-up of the later process of innovation outputs is beyond the scope of this study.

\section{Hackathon design elements driven practices}

As various hackathon events include design elements, these elements require also practices to be applied from the hackathon organizer viewpoint, since they may enhance the hackathon's success (Figure 1). There are at least four essential general practices that were identified during the Urban-Educational hackathon case:

1. Goal and task-setting practices include the specification of the hackathon's goals, and furthermore the task or tasks the hackathon aims to address.

2. Ideation continuum practices signify the benefits of design thinking throughout the hackathon process from pre-hackathon to post-hackathon phases. Thus, the tasks and the exercises do not appear unattached, but rather flow in a way that constitutes a solid experience to the participant.

3. Team formation practices incorporate social learning among participants and their various characteristics, thus choosing the most beneficial team formation method for the event.

4. Forming a proximity of location means that the object of the hackathon, e.g. a city aiming at getting 'smarter', should be familiarized to the participants with physical, mental or spiritual artifacts.

\section{Hackathon outputs}

The three student groups generated different conceptual innovations. Two of the innovations were technological, combining service product concepts, and the third combined logistics and service concepts.

\section{Conclusions}

This article contributes to the literature of innovation management methods, particularly to the concept and method of the hackathon as an innovation contest. More specifically, by responding to the call by Pe-Than et al. (2019) to study different design elements and their effectiveness with respect to the intended event goals, this article contributes to the design of dual-focus hackathons, combining educational and urban hackathons, and their innovation outputs. By answering our first research question, "What kind of process and practices did a hackathon event, designed with a dualfocus, i.e. combined educational-urban hackathon, consist of?", we contribute by describing the process and design elements of a dual-focus hackathon, which aimed at both learning, and the creation of innovations to benefit the city in question.

As an educational hackathon, the hackathon process was designed to include training both in the prehackathon phase, as well as in the hackathon event itself, and additionally during the event with coaching. As an urban hackathon, the task was set for a city domain, aiming to create value-adding solutions for the city centre users, either physical, intangible, digital, or a combination of them. Therefore, our results add to the previous studies of general, civic, and urban hackathons by Almirall et al. (2014), Granados and Pareja-Eastaway (2019), Komssi et al. (2015), Pogačar and Žižek (2016), and Rosell et al. (2014), by clarifying the significance that the hackathon design element of focus, and especially

Table 3. The three innovations generated in the educational-urban hackathon in Rauma

\begin{tabular}{lll}
\hline Generated innovations & Innovation type \\
\hline 1. & $\begin{array}{l}\text { Smartphone application } \\
\text { Displays entertainment in Rauma e.g., events, restaurants } \\
\text { with their menus, hotels, and shopping opportunities. }\end{array}$ & $\begin{array}{l}\text { Combines technology and service product } \\
\text { concept innovation }\end{array}$ \\
2. $\begin{array}{l}\text { Gamified smartphone application built on Rauma map } \\
\text { The application would apply augmented reality, including } \\
\text { stories and games of local historical events. }\end{array}$ & $\begin{array}{l}\text { Combines technology and service concept } \\
\text { product innovation }\end{array}$ \\
3. Non-stop electric bus route \& gateway & $\begin{array}{l}\text { Connects Old Rauma with rest of the city. Improves the Old } \\
\text { Rauma entry with a prestige gateway }\end{array}$ & innovation \\
\hline
\end{tabular}




\section{Anu Helena Suominen, Seija Halvari \& Jari Jussila}

dual-focus, has on the goals and process of the hackathon event.

In addition, we identified four practices that are connected to and driven by hackathon design elements: 1) Goal and task-setting, 2) Formation of the ideation continuum, 3) Team formation, and 4) Forming the proximity of location. From the organizer viewpoint, at least these four practices should be adopted while designing an Educational-Urban hackathon, since they may enhance the hackathon's success. Moreover, this article responds to the call for more research to assess the impacts and outcomes of hackathons by Gama (2017), and Johnson and Robinson (2014). By answering our second research question, "What kind of output did a combined educational-urban hackathon achieve in terms of its dual focus and goal setting?", we make a contribution by presenting the three urban innovation outputs generated by the students of an RDI course during a hackathon. The outputs were two different smartphone application concepts, as well as one logistics and service concept. Therefore, our results add to the previous civic and urban hackathon studies by Lodato and DiSalvo (2015) and Pogačar and Žižek (2016), particularly by describing a generated urban innovation output. Secondly, the results consolidate the view of Pogačar and Žižek (2016) that urban hackathons have moved away from pure coding, toward concrete proposals.

In general, scientific research on hackathons is scarce and mainly descriptive, concerning software solutions and applications. According to Pe-Than et al. (2019), the study of hackathon design elements in particular is practically non-existent. Our results showed that hackathons could have a dual focus, and thus multiple goals. Therefore, we believe educational and urban hackathons can be combined to produce multiple goals. However, in task setting, both of these focuses have to be considered when designing the event.

Firstly, with students as participants, innovation training is an important part of the event design, in order to achieve the targeted learning outcome. Secondly, when the goal is to achieve urban innovations that truly benefit the city domain, the task should be bounded in order to gain innovations with the targeted level of sophistication. Yet, just as students used their education and knowledge to create innovations, the hackathon as a method could very well also be adopted in city collaboration with the public. Taking into account the fact that participants may have various backgrounds and carefully designing the task accordingly, it would be more likely that public output could achieve the goals set by the city.

Our hackathon case was carried out in the context of an inhabited World Heritage city, which aims to stay competitive in face of challenges from modern urban cities. Therefore, our results benefit both lecturers in HEIs teaching innovation, as well as cities aiming to collaborate with HEIs for urban innovation. Our results present an encouraging example for other cities to use participatory methods, such as hackathons, especially dual-focus educational-urban hackathons, in collaboration with HEIs to generate not only learning, but also usable urban innovations. Therefore, our results give a vivid example of how cities can integrate universities in particular into their innovation practices, as suggested by Kunttu (2019), and Markkula and Kune (2018), using the hackathon method. From an innovation management standpoint, having functioning methods for innovation, and especially idea generation and evaluation, is an essential feature of teaching and utilizing innovation in various domains. Thus, we claim that the dual-focus educational-urban hackathon, when designed properly, is a practical functioning method for cities aiming at urban innovations and smart city development. 


\section{World Heritage meets Smart City in an Urban-Educational Hackathon in Rauma}

\section{Anu Helena Suominen, Seija Halvari \& Jari Jussila}

\section{References}

Adamczyk, S., Bullinger, A. C., \& Möslein, K. M. 2012. Innovation Contests: A Review, Classification and Outlook. Creativity and Innovation Management, 21(4): 335-360.

Almirall, E., Lee, M., \& Majchrzak, A. 2014. Open innovation requires integrated competitioncommunity ecosystems: Lessons learned from civic open innovation. Business Horizons, 57(3): 391-400.

Angarita, A. M. M., \& Nolte, A. 2019. Does it matter why we hack? -Exploring the impact of goal alignment in hackathons. Proceedings of the 17th European Conference on Computer- Supported Cooperative Work: The International Venue on Practice-centred Computing and the Design of Cooperation Technologies - Exploratory Papers, Reports of the European Society for Socially Embedd, 1-15.

Bouncken, R. B., Gast, J., Kraus, S., \& Bogers, M. 2015. Coopetition: a systematic review, synthesis, and future research directions. Review of Managerial Science, 9(3): 577-601.

Briscoe, G., \& Mulligan, C. 2014. Digital Innovation: The Hackathon Phenomenon. Creativeworks London, (6): $1-13$.

Carlson, C.R., \& Wilmot, W. W. 2006. Innovation: the five disciplines for creating what customers want. Crown Business.

Chowdhury, J. 2018. Hacking Health: Bottom-up Innovation for Healthcare. Technology Innovation Management Review, 2(7): 31-35.

Cities - Organization of World Heritage Cities. n.d.. https://www.ovpm.org/cities/, May 21, 2019.

Cross, N. 2008. Engineering design methods: Strategies for product design (4th ed.).

https://doi.org/10.1016/0261-3069(95)90023-3.

Dameri, R. P. 2013. Searching for Smart City definition: a comprehensive proposal. International Journal of Computers \& Technology, 11(5): 2544-2551.

Dascalu, M. I., Bodea, C. N., Lytras, M., De Pablos, P. O., \& Burlacu, A. 2014. Improving e-learning communities through optimal composition of multidisciplinary learning groups. Computers in Human Behavior, 30: 362-371.

DiSalvo, C., Gregg, M., \& Lodato, T. 2014. Building belonging. Interactions, 21(4): 58-61.

Gama, K. 2017. Preliminary ndings on Software Engineering Practices in Civic Hackathons. IEEE 4th International Workshop on CrowdSourcing in Software Engineering (CSI-SE), 14-20.

Granados, C., \& Pareja-Eastaway, M. 2019. How do collaborative practices contribute to innovation in large organisations? The case of hackathons. Innovation, 00(00): 1-19.

Halvari, S., Suominen, A., Jussila, J., Jonsson, V., \& Bäckman, J. 2019. Conceptualization of hackathon for innovation management. The ISPIM Innovation Conference - Celebrating Innovation: 500 Years Since daVinci. ISPIM.
Hartmann, S., Mainka, A., \& Stock, W. G. 2019a. Innovation contests: how to engage citizens in solving urban problems? Civic engagement and politics: concepts, methodologies, tools, and applications: 58-77. IGI Global.

Hartmann, S., Mainka, A., \& Stock, W. G. 2019b. Opportunities and Challenges for Civic Engagement: A Global Investigation of Innovation Competitions. Civic engagement and politics: concepts, methodologies, tools, and applications: 607-623.

Johnson, P., \& Robinson, P. 2014. Civic Hackathons: Innovation, procurement, or civic engagement? Review of Policy Research, 31(4): 349-357.

Kärkkäinen, H., Piippo, P., \& Tuominen, M. 2001. Ten tools for customer-driven product development in industrial companies. International Journal of Production Economics, 69: 161-176.

Kienzler, H., \& Fontanesi, C. 2017. Learning through inquiry: a Global Health Hackathon. Teaching in Higher Education, 22(2): 129-142.

Komssi, M., Pichlis, D., Raatikainen, M., Kindstrom, K., Jarvinen, J., et al. 2015. What are Hackathons for? IEEE Software, 32(5): 60-67.

Kunttu, I. 2019. Developing smart city services by mobile application. ISPIM Florence Conference Proceedings.

Leckart, S. 2012. The Hackathon Is On: Pitching and Programming the Next Killer App. Wired. https://www.wired.com/2012/02/ff_hackathons/.

Lodato, T.J., \& DiSalvo, C. 2015. Issue-oriented hackathons as material participation. New Media and Society, 18(4): 539-557.

Markkula, M., \& Kune, H. 2018. Making Smart Regions Smarter: Smart Specialization and the Role of Universities in Regional Innovation Ecosystems. Technology Innovation Management Review, 5(10): $7-15$.

Mulder, I. 2014. Sociable Smart Cities: Rethinking Our Future through Co-creative Partnerships. In N. Streitz \& P. Markopoulos (Eds.), Distributed, ambient, and pervasive interactions: Sedonc international conference, DAPI 2014 held as part of Heraklion, Crete, Greece, June 22-27, 2014, 566-574. Springer.

Öberg, C., Graham, G., \& Hennelly, P. 2017. Smart cities: A literature review and business network approach discussion on the management of organisations. IMP Journal, 11(3): 468-484.

Ojasalo, J., \& Kauppinen, H. 2018. Collaborative Innovation with External Actors: An Empirical Study on Open Innovation Platforms in Smart Cities. Technology Innovation Management Review, 6(12): $49-60$.

Pe-Than, E. P. P., \& Herbsleb, J. D. 2019. Understanding Hackathons for Science: Collaboration, Affordances, and Outcomes. In N. G. Taylor, C. Christian-Lamb, M. H. Martin, \& B. Nardi (Eds.), Information in Contemporary Society, Proceedings of 14th International Conference, iConference, 27-37. Washington, DC, USA: Springer. 


\section{World Heritage meets Smart City in an Urban-Educational Hackathon in Rauma}

\section{Anu Helena Suominen, Seija Halvari \& Jari Jussila}

Pe-Than, E. P. P., Nolte, A., Filippova, A., Bird, C., Scallen, S., et al. 2019. Designing Corporate Hackathons With a Purpose. IEEE Software, (January): $15-22$.

Pogačar, K., \& Žižek, A. 2016. Urban Hackathon Alternative Information Based and Participatory Approach to Urban Development. Procedia Engineering, 161: 1971-1976.

Porras, J., Knutas, A., Ikonen, J., Happonen, A., Khakurel, J., et al. 2019. Code camps and hackathons in education-literature review and lessons learned. Proceedings of the 52nd Hawaii International Conference on System Sciences, 7750-7759.

Roders, A. P., \& van Oers, R. 2011. World Heritage cities management. Facilities, 29(7): 276-285.

Rosell, B., Kumar, S., \& Shepherd, J. 2014. Unleashing innovation through internal hackathons. Digest of Technical Papers - InnoTek 2014: 2014 IEEE Innovations in Technology Conference. https://doi.org/10.1109/InnoTek.2014.6877369.

Siggelkow, N. 2007. Persuation with Case Studies. Academy of Management Journal, 50(1): 20-24.

Slåen, T., Mantere, V., Tollet, L., \& Karisto. 2003. Opera: a guide for more efficient meetings. Innotiimi. https://books.google.fi/books/about/Opera.html?id= h78zAwAACAAJ\&redir_esc=y.

Statistics Finland. 2018. Population, Statistics Finland.

Suominen, A. H., Jussila, J., Lundell, T., Mikkola, M., \& Aramo-Immonen, H. 2018. Educational Hackathon: Innovation Contest for Innovation Pedagogy. In I. Bitran, S. Conn, K. R. E. Huizingh, O. Kokshagina, M. Torkkeli, et al. (Eds.), XXIX ISPIM Conference "The Name of the Game." Stockholm.

Teasley, S., Covi, L., Krishnan, M. S., \& Olson, J. S. 2000. How does radical collocation help a team succeed? $A M C$ conference on CSCW 2000, 339-346. Philadelphia, PA, USA.

Visvizi, A., \& Lytras, M. D. 2018. Rescaling and refocusing smart cities research: from mega cities to smart villages. Journal of Science and Technology Policy Management, 9(2): 134-145.

Zukin, S., \& Papadantonakis, M. 2017. Hackathons as Co-optation Ritual: Socializing Workers and Institutionalizing Innovation in the "New" Economy. Precarious Work.

https://doi.org/http://dx.doi.org/10.1108/VINE-102013-0063.

\section{About the Authors}

Anu Helena Suominen, D.Sc. (Tech.), is a university teacher at Tampere University, Finland. She defended her doctoral thesis on legitimacy building in inter-organizational networks in 2017. Besides working for years in the field of research and education, Anu has several years of practical working experience in industry: in export, managing networking, and training projects. Anu is responsible for teaching four Master's level courses in Knowledge Management, Innovation, Procurement, and Project Business Management. Her research is currently focused on hackathons for both industrial and educational purposes, knowledge sharing and integration, and innovation in inter-organizational networks.

Seija Halvari, M.Sc. (Tech.) and B.Eng., is a lecturer in Häme University of Applied Sciences (HAMK). Her research has focused on startup companies' business model evolution and innovations. In addition, she has studied hackathons in an industrial and educational context. Seija has a strong industrial background and over a decade of experience in external and internal project management in various positions, together with experience in IT systems and business process improvement.

Dr. Jari Jussila holds a $\mathrm{PhD}$ in Knowledge Management from Tampere University of Technology (TUT, 2015). At present, he is Principal Research Scientist at Häme University of Applied Sciences (HAMK). His research is currently focused on knowledge management, business intelligence, social media, big social data analytics, and health informatics. His works have been published in such international journals as Computers in Human Behavior, Industrial Management \& Data Systems, International Journal of Knowledge Management, and Knowledge Management Research \& Practice.

Citation: Suominen, A.H., Halvari, S. \& Jussila, J. 2019 World Heritage meets Smart City in an Urban-Educational Hackathon in Rauma. Technology Innovation Management Review, 9(9): 44-53.

http://doi.org/10.22215/timreview/1268/

(cc) BY

Keywords: Innovation contest, Hackathon, Urban

hackathon, Educational hackathon, Smart city 


\section{TIM Technology Innovation Management Review

\section{Academic Affiliations and Funding Acknowledgements}
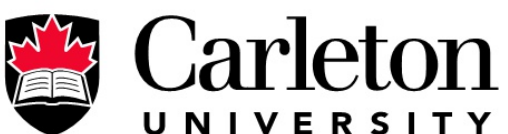
U N I V E R S I T Y

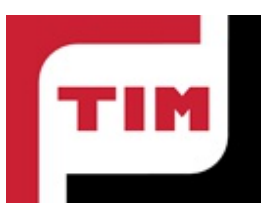

Technology Innovation Management (TIM; timprogram.ca) is an international master's level program at Carleton University in Ottawa, Canada. It leads to a Master of Applied Science (M.A.Sc.) degree, a Master of Engineering (M.Eng.) degree, or a Master of Entrepreneurship (M.Ent.) degree. The objective of this program is to train aspiring entrepreneurs on creating wealth at the early stages of company or opportunity lifecycles.

The TIM Review is published in association with and receives partial funding from the TIM program.

The TIM Review team is a key partner and contributor to the Scale Early, Rapidly and Securely (SERS) Project: https://globalgers.org/. Scale Early, Rapidly and Securely (SERS) is a global community actively collaborating to advance and disseminate high-quality educational resources to scale companies.

The SERS community contributes to, and leverages the resources of, the TIM Review (timreview.ca). The authors, readers and reviewers of the TIM Review worldwide contribute to the SERS project. Carleton University's Technology Innovation Management (TIM) launched the SERS Project in 2019.

We are currently engaged in a project focusing on identifying research and knowledge gaps related to how to scale companies. We are inviting international scholars to join the team and work on shaping Calls for Papers in the TIM Review addressing research and knowledge gaps that highly relevant to both academics and practitioners. Please contact the Editor-inChief, Dr. Stoyan Tanev (stoyan.tanev@carleton.ca) if you want to become part of this international open source knowledge development project. 